\title{
Diabetic Nephropathy - a Review of Risk Factors, Progression, Mechanism, and Dietary Management
}

\author{
Vijayakumar Natesan ${ }^{1}$ and Sung-Jin $\mathrm{Kim}^{2, *}$ \\ ${ }^{1}$ Department of Biochemistry and Biotechnology, Faculty of Science, Annamalai University, Annamalainagar-608002, Tamilnadu, \\ India \\ ${ }^{2}$ Department of Pharmacology and Toxicology, Metabolic Diseases Research Laboratory, School of Dentistry, Kyung Hee University, \\ Seoul 02447, Republic of Korea
}

\begin{abstract}
Type 2 diabetes mellitus (T2DM) leads to many health problems like diabetic nephropathy (DN). One of the key factors for chronic kidney disease and end-stage renal disease (ESRD) is T2DM. Extensive work is being done to delineate the pathogenesis of DN and to extend possible remedies. This review is intended to understand the nature of DN risk factors, progression, effects of glycemic levels, and stages of DN. We also explored the novel diagnostic and therapeutic approaches for DN such as gene therapy and stem cell treatments.
\end{abstract}

Key Words: Diabetic nephropathy, Kidney disease, Hyperglycemia, Novel drugs

\section{INTRODUCTION}

Diabetic nephropathy (DN) is a major disorder of diabetes mellitus (DM) which ends up in chronic renal failure (Schrijvers et al., 2004; Sulaiman, 2019). People with DM are ten times more prone to end-stage kidney failure. The International Diabetes Federation (IDF) reports that $40 \%$ of diabetic people might develop final stage renal failure. Furthermore, diabetes and hypertension, either in combination or separately lead to about $80 \%$ of end-stage kidney failure (Hill et al., 2016).

Microalbuminuria is the early evidence for detecting DN About $20 \%$ of patients develop nephropathy from microalbuminuria within a decade and nearly $20 \%$ of patients reach endstage kidney disease. On one hand, around $20 \%$ of T1DM patients suffer from end-stage kidney failure in just a decade, and $75 \%$ of patients in less than two decades as there is no treatment available to date. On the other hand, T2DM patients show evidence of microalbuminuria and nephropathy within a short period of DM diagnosis (Shahbazian and Rezaii, 2013; Pugliese et al., 2020).

An early symptom of DN includes high excretion of albumin in urine, glomerular and renal hypertrophy, hyperfiltration, and mesangial expansion with ECM proteins aggregation such as fibronectin, laminin, and collagen (Schrijvers et al., 2004). Re- cent developments in diagnostics and therapeutics such as the study of innovative molecules, stem cell therapy, and gene therapies are necessary for the treatment of DN (Rota et al., 2019). However, concomitant medication such as drugs for hypertension, dyslipidemia, etc., complicates the understanding of DN and further increases the complexity of preventive and therapeutic measures. The purpose of the review is to compile the knowledge of DN risk factors, prevalence, diagnostics, and therapeutic strategies for DN from existing literature.

\section{RISK FACTORS}

Risk factors were defined as two types for DN: modifiable and non-modifiable factors. Modifiable factors include hypertension, glycemic level management, and dyslipidemia. Additionally, Scott et al. (2001) and Börnhorst et al. (2020) demonstrated smoking as an additional modifiable risk factor. Non-modifiable factors are race, age, gestation, genetic profile, and sex. Patients with a family history of DN family history were more susceptible to develop the condition (Pettitt et al., 1990; Werner et al., 2018). A race such as the American population of Mexicans, Africans, and Pima people of Native

\section{Open Access https://doi.org/10.4062/biomolther.2020.204}

This is an Open Access article distributed under the terms of the Creative Commons Attribution Non-Commercial License (http://creativecommons.org/licenses/by-nc/4.0/) which permits unrestricted non-commercial use, distribution, and reproduction in any medium, provided the original work is properly cited.
Received Nov 11, 2020 Revised Jan 18, 2021 Accepted Mar 26, 2021

Published Online Apr 23, 2021

\section{*Corresponding Author}

E-mail: kimsj@khu.ac.kr Tel: +82-2-961-0868 
Americans showed higher rates of developing DN. Concerning sex, male DM patients have higher possibilities of DN (Gall et al., 1997; Young et al., 2003; Narres et al., 2016).

Genes, such as ACE, APOC1, GREM1, UNC13B, ALR2, APOE, CARS, CPVL/CHN2, eNOS, EPO, FRMD3, HSPG2, and VEGF, are identified for the hereditary reasons of DN. ELMO1, CCR5, and CNDP1 were identified to be the reason for ND in a subgroup of T2DM Asian subjects. Polymorphic genes of ADIPOQ, PAI-1, TGF $\beta 1$, and PPAR $\gamma$ also have been studied and shown their crucial role in developing DN (Dellamea et al., 2014). High levels of $\mathrm{HbA} 1 \mathrm{C}$, proteinuria, systolic blood pressure, and habits increase the risk of DN in DM patients (Eberhard, 2006; Lu et al., 2017).

\section{STAGES OF DIABETIC NEPHROPATHY}

The initial phase of DN starts with the glomerular basement membrane (GBM) thickening. Normal glomerular filtration rate (GFR), lack of albuminuria, and hypertension are often observed in this stage for five years from the onset of GBM thickening. The next stage involves the development of mild to severe mesangial expansion. Two years from the onset of the GBM thickening and mesangial proliferation, normal GFR were still observed and no other clinically significant symptoms were recorded (Tervaert et al., 2010). The third stage is the damage of glomerular and elevated microalbuminuria of 30 to $300 \mathrm{mg} \mathrm{day}^{-1}$. The stage was observed in diabetic patients with or without the condition, hypertension. The third stage is called nodular sclerosis and starts after 5 to 10 years from GBM onset. The advanced diabetic glomerulosclerosis is the fourth stage of DN in which tubulointerstitial and vascular lesions are prominent. The end-stage is the total kidney failure

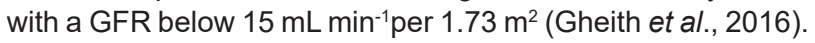

\section{PROGRESSION OF DIABETIC NEPHROPATHY}

As not every diabetic patient advance to macroalbuminuria, microalbuminuria serves to diagnose DN. Normal albumin levels may be regressed in some patients. Type 2 DM patients show high variability in DN progression. The variability is evident as DN is mostly considered as a secondary disorder of DM and onset date is often under-diagnosed (Caramori et al., 2000). Recent research showed $38 \%$ of patients develop microalbuminuria and $29 \%$ showed decreased GFR after 15 years of follow-up. Additionally, they reported a progression of $2.8 \%$ from microalbuminuria and $2.3 \%$ from GFR to ESRD (Retnakaran et al., 2006). Gheith et al. (2016) mentioned that the progression of renal disease was gradually increasing at $17.3 \%, 24.9 \%$, and $24.9 \%$ for the first 5 years, 10 years, and 15 years from the date of diagnosis.

\section{IMMEDIATE AND LATE EFFECTS OF HYPERGLYCEMIA}

Hyperglycemia is found to raise the level of glucose strained over the glomerular filtration in the proximal tube leading to glucose hyper-reabsorption. During hyper-reabsorption of glucose, glucose transporter expression is triggered and enormous changes in energy-absorbing transfer systems are observed in the proximal tubular cells (Vallon, 2015). This mechanism significantly raises the demand for oxygen in the renal cortex and outer medulla resulting in ischemia and enhancing stress markers' expressions like kidney injury molecule 1 (KIM1) and neutrophil gelatinase-associated lipocalin (NGAL) (Zeni et al., 2017). The increased stress of the proximal tubule results in hypertrophy and elongation in the proximal tubule, and subsequent kidney hypertrophy. The sodium retrieval is increased tremendously in the proximal tubule when SGLT2 co-transports sodium, thus lowering the $\mathrm{NaCl}$ concentration at macula densa and in the distal tubule. The lower concentration of $\mathrm{NaCl}$ disables the process of tubule-glomerular feedback and triggers renal afferent arteriole dilation at macula densa (Anders et al., 2016; Perry and Shulman, 2020). The concurrent production of renin improves the efferent arteriole's vasoconstriction. Glomerular hypertension, glomerular hyperfiltration, and a steady rise in single- nephron GFR are the results of the hemodynamic effects. Though glomerular pressure is declining due to the development of glomerular hypertrophy, glomerular hyperfiltration continues (Amalan and Vijayakumar, 2015; Neal et al., 2017). The role of SGLT2 and renin in these systems might help to answer the reasons for the effects of SGLT2 and RAS inhibition over a very short period on renal hemodynamics in diabetic kidney disease (DKD) patients.

In comparison to positive results of addressing the upstream hemodynamic routes described above, the late causes of hyperglycemia can have various effects, especially in mixed groups of patients with DKD against NDKD-DM patients, focusing the downstream and postponed impacts of hyperglycemia, e.g., inflammation and endothelial dysfunction (Wanner et al., 2016). However, to help the implementation of therapeutic options for ESRD patients, an understanding of these downstream consequences is needed.

\section{MECHANISMS OF DKD (DIABETIC KIDNEY DISEASE)}

Hyper aminoacidemia, a glomerular hyperfiltration promoter, and hyperglycemia are the metabolic modifications that change renal hemodynamics and facilitate fibrosis and inflammation in diabetes' initial stage (Fig. 1). In this study, the pathways that drive the development of chronic kidney disease (CKD) in DM patients are studied to provide a conceptual basis for identifying effective therapeutic targets. DN is a significant DM microvascular disorder responsible for $50 \%$ of all ESRD populations (Saran et al., 2017).

In hypertensive patients, DKD is also a significant reason for cardiovascular risk. Microalbuminuria acts as the first clinical expression of DKD and almost $50 \%$ of microalbuminuria patients will advance to macroalbuminuria without an early diagnosis. The chance of ESRD progression is almost ten times greater than the patients with normal urinary albumin levels (Berhane et al., 2011). The crucial factors for the existence of microalbuminuria in T2DM patients are high urinary albumin to creatinine ratio, high $\mathrm{HbA} 1 \mathrm{c}$ level, older age hypertension, and increased blood glucose levels. Hemodynamic factors such as eGFR may not play a part (Amalan et al., 2015).

Roughly $30 \%$ of T1DM patients are associated with microalbuminuria and rely on blood glucose control and drug compliances (Oh et al., 2012; Chatzikyrkou et al., 2017). There 


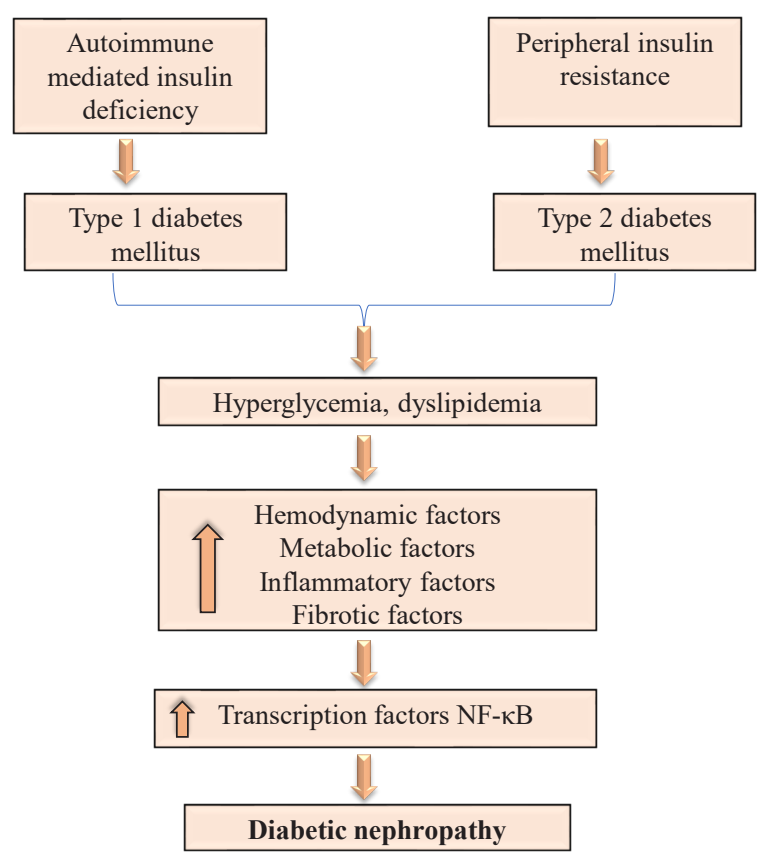

Fig. 1. The schematic overview of inflammatory mechanisms in the pathophysiology of diabetic nephropathy (DN). The initiation and progression of DN is involved in metabolic and hemodynamic disruption. In DN, hyperglycemia-induced metabolic destruction is the major reason for the development and progression of diabetic nephropathy.

is a chance of $30 \%$ of T2DM patients to develop microalbuminuria and are interrelated to hypertension (Ahmad et al., 2017; Smith and Harris, 2018). In the aforementioned cases, albuminuria is related to hypertension, and uncontrolled blood glucose levels represent a significant part in the development of overt DN.

Good control of the $\mathrm{HbA} 1 \mathrm{c}$ level can avoid progression to ESRD and it demonstrates the significance of hyperglycemia in the development of DKD in T1DM patients (Fu et al., 2019). The risk factors for DKD are identified as low birth weight, morbid obesity, glycemic control, and genetic susceptibility which interprets that not all DM patients are interconnected to DKD (Skupien et al., 2014; Tonneijck et al., 2017). To analyze the variations in the pathological processes of DKD and NDKD, it is also suggested to explore the initial and later consequences of hyperglycemia on the kidney.

\section{DIAGNOSIS}

For both T1DM and T2DM, serum TNF- $\alpha$ receptor level is the most effective diagnostic tool and forecasts the development of CKD and ESRD. In type II diabetics, besides albuminuria, the levels of TNF- $\alpha$ receptor exhibited as a significant predictive factor. Furthermore, serum uric acid acts as a biomarker and pathogenic (Niewczas et al., 2012; Kopel et al., 2019).

Beta-trace protein (beta TP), microRNA-130b, and NGAL are recently explored as valuable biomarkers for diagnosis in T2DM patients (Motawi et al., 2018). In T2DM patients, NGAL and beta TP are present at a higher level than normal and this helps glomerular and tubular markers as primary biomarkers, respectively. The tubular biomarkers are listed in Table 1. Many recent reviews showed the advantages of biomarkers in earlier DKD identification (Papadopoulou-Marketou et al., 2017). In the future, progress in metabolic phenotyping and biomarkers study provide confidence for multiparametric risk evaluation of renal injury and efficient interventions. In comparison to conventional prediction models, broader studies have not demonstrated that these biomarkers provide added benefit. However, to understand the role of biomarkers in clinical practice, additional work is required.

\section{TREATMENT}

The key treatment choices for DN are maintenance of blood glucose levels, hypertension, hemodynamic control, and other metabolic disorders (Satko et al., 2002). Concluding and comparing all glucose-lowering agents is outside the study's objective, but beyond glucose-lowering, some agents have conceptual advantages, and they are discussed in our study. Some antihypertensive medications have shown benefits in reducing proteinuria or GFR. Alternative drugs and non-pharmacological methods are also explored. Novel agents, stem cell treatment, and gene therapy are being extensively studied in the treatment of DKD.

\section{IMPORTANCE OF DIET THERAPY FOR NEPHROPATHY}

The goal of diabetic nephropathy therapy is to preclude the macroalbuminuria development from microalbuminuria and continual drop in kidney function and related cardiac disorders. The major cornerstones are antihypertensive therapy by blocking the RAAS pathway, lipid-modifying statins, and intensive glycemic control. A thorough discussion of different diabetic nephropathy treatment approaches is presented in this study. In DN procedures and outcomes, the dietary state of patients is a significant factor (Oltean et al., 2017). In sustaining an individual's nutritional status, diet control is considered an essential part. Although diabetes encourages a balanced and stable diet; it is difficult for CKD diets to slow the kidney damage's progression and related secondary disorders such as hyperlipidemia, hypertension, and uremia. Continuous supervision is required and must be patient and treatment specific.

A fragile, healthy diet between nutrition and maintainable physiological activities are necessary to preserve the patient's life quality. The issues faced in kidney failure failures and proteinuria are unawareness of dietary follow-up and continuous intake of conventional diet options which are high in minerals, proteins, and carbohydrates. Restricting fat consumption is the only regulation that must be exercised in dyslipidemia patients. Such an uneven diet imposes a burden on the activity of the kidney, resulting in more disease control issues. An ideal diet prescribed for diabetic nephropathy patients is a proper amount of fat consumption. Moreover, it is also important to limit total calories from the consumption of protein and carbohydrates. As recommended by earlier research, a complete reduction in fat can be a very dangerous activity. Nutritionist 
Table 1. List of tubular biomarkers

\begin{tabular}{|c|c|c|c|}
\hline Bio marker & Source & Size & Key point \\
\hline MMP-9 & Macrophages & 707 kDa & $\begin{array}{l}\text { MMP-9 functions as proapoptotic element in rapid depletion of retinal } \\
\text { capillary cells seen in diabetic retinopathy pathogenesis (Kowluru, } \\
\text { 2010). }\end{array}$ \\
\hline MMP-2 & $\begin{array}{l}\text { Cardiomyocytes, fibroblasts, and } \\
\text { myofibroblasts. }\end{array}$ & $72 \mathrm{kDa}$ & $\begin{array}{l}\text { MMPs are a large proteinase family that redesigns constituents of the } \\
\text { extracellular matrix. Its induction is known as negative regulation of } \\
\text { cell viability under pathological environments (Mohammad and Sid- } \\
\text { diquei, 2012). }\end{array}$ \\
\hline TNF- $\alpha$ & $\begin{array}{l}\text { Macrophages, dendritic cells, natu- } \\
\text { ral killer cells, and T lymphocytes }\end{array}$ & $17.3 \mathrm{kDa}$ & $\begin{array}{l}\text { Renal cells synthesize tumor necrosis factor (TNF)- } \alpha \text { and is a cyto- } \\
\text { kine with primarily proinflammatory functions (Navarro et al., 2005). }\end{array}$ \\
\hline IL-6 & Smooth muscle cells & $21-26 \mathrm{kDa}$ & $\begin{array}{l}\text { Interleukin (IL)- } 6 \text { is a cytokine with proinflammatory factor. Elevated } \\
\text { vitreous IL-6 expression in patients with DR is associated with } \\
\text { macular oedema. Although, the essential purpose of IL-6 remains } \\
\text { uncertain in DR pathogenesis (Rojas et al., 2011). }\end{array}$ \\
\hline RBP4 & Liver & $21 \mathrm{kDa}$ & $\begin{array}{l}\text { RBP4 is related to insulin resistance factors and diabetic related dis- } \\
\text { orders (Li et al., 2018). }\end{array}$ \\
\hline IGF-1 & Cartilaginous cells & $7649 \mathrm{kDa}$ & $\begin{array}{l}\text { IGF-1 is considered to activate a sequence of molecular mechanisms } \\
\text { which causes retinal angiogenesis. Accelerated vitreous IGF-1 lev- } \\
\text { els related to incidence of diabetic retinal neovascularization related } \\
\text { to severe ischemia (De Sanctis et al., 2015). }\end{array}$ \\
\hline VEGF & Macrophages, platelets & $46 \mathrm{kDa}$ & $\begin{array}{l}\text { VEGF development is triggered because of ischemia or hypoxia. Tis- } \\
\text { sue hypoxia contributes to the formation of a protein called hypoxia- } \\
\text { inducible factor } 1 \text { (HIF-1) that binds to DNA (Krock et al., 2011). }\end{array}$ \\
\hline \multirow[t]{3}{*}{$\mathrm{KIM}-1$} & Blood retinal & 124 kDa & $\begin{array}{l}\text { Baseline KIM-1 had a predicted rate of loss in eGFR and eSRD in } \\
\text { proteinuric patients (>500 mg day-1) over } 5-15 \text { years of continuity } \\
\text { (Sabbisetti et al., 2014). }\end{array}$ \\
\hline & Urine & $63 \mathrm{kDa}$ & $\begin{array}{l}\text { KIM-1 is correlated with GFR reduction but albuminuria-dependent } \\
\text { (Nielsen et al., 2011). }\end{array}$ \\
\hline & Urine & $978 \mathrm{kDa}$ & $\begin{array}{l}\text { Urine KIM-1/Cr is linked to initial GFR drop with a 4-year follow-up but } \\
\text { does not have more prognostic details to albumin/Cr ratio (Conway } \\
\text { et al., 2012). }\end{array}$ \\
\hline \multirow[t]{3}{*}{ NGAL } & Serum/urine & $50 \mathrm{kDa}$ & $\begin{array}{l}\text { NGAL shows a raised level prior to microalbuminuria. Urine NGAL is } \\
\text { interlinked with albuminuria and serum NGAL is known to be related } \\
\text { with HbA1c (Lacquaniti et al., 2013). }\end{array}$ \\
\hline & Serum/urine & $63 \mathrm{kDa}$ & $\begin{array}{l}\text { NGAL is consistent with GFR decline, but albuminuria-dependent } \\
\text { (Nielsen et al., 2011). }\end{array}$ \\
\hline & Urine & $140 \mathrm{kDa}$ & Urine NGAL is not related to eGFR (Chou et al., 2013). \\
\hline \multirow[t]{3}{*}{ L-FABP } & Urine & $1549 \mathrm{kDa}$ & $\begin{array}{l}\text { The range of differing L-FABP results were observed between normo- } \\
\text { albuminuria and macro-albuminuria. The urine L-FABP/Cr ratio pre- } \\
\text { dicted DN progression at baseline, however the addition of L-FABP } \\
\text { to albumin excretion did not provide the predictive models (Panduru } \\
\text { et al., 2013). }\end{array}$ \\
\hline & Urine & $277 \mathrm{kDa}$ & $\begin{array}{l}\text { Urine L-FABP could predict albuminuria progression or death (Nielsen } \\
\text { et al., 2014). }\end{array}$ \\
\hline & Urine/serum & $63 \mathrm{kDa}$ & L-FABP is not consistent with GFR decrease (Nielsen et al., 2011). \\
\hline Cystatin C & Urine & $237 \mathrm{kDa}$ & $\begin{array}{l}\text { The urine cystatin } \mathrm{C} / \mathrm{Cr} \text { ratio is linked with eGFR reduction, with ele- } \\
\text { vated tertile levels correlated with advancement to stage } 3 \text { or higher } \\
\text { CKD after continuation of } 20 \text { months (Kim et al., 2013). }\end{array}$ \\
\hline
\end{tabular}

This shows a list of renal tubular biomarkers that could help to identify diabetic nephropathy.

recommends reducing the intake of saturated fatty acids and consuming unsaturated fat foods such as omega-rich fatty oils and plant-based oils at a low level (Otoda et al., 2014). Also, a protein intake of 0.6 to $0.7 \mathrm{~g} \mathrm{~kg}^{-1}$ day $^{-1}$ is recommended with personalized nutritional strategies to prevent malnutrition in the general management of renal insufficiency (Trimeche et 
al., 2013; Zha and Qian, 2017). Moreover, several clinical trials showed the advantages of minimal protein intake on DN and insist that protein limitation is not only a suggestion to provide complete control.

A very low protein diet (VLPD) in animal T2DM models reduced tubule interstitial injury, inflammation, and fibrosis by restoring autophagy besides reducing mammalian target of rapamycin complex 1 (mTORC1) activity (Kitada et al., 2018). An LPD can delay the development of kidney disorder in people with chronic glomerular nephritis. For DN patients, a low salt diet and low-pickled fruit are strongly recommended. Low sodium consumption decreases blood pressure. The annual creatinine clearance drop in patients with T2DM DN was correlated with higher salt consumption and excretion of urinary protein (Kanauchi et al., 2015). In the event of a patient's deficiency in kidney function due to retention in body tissues, potassium excretion is further decreased. However, potassium is necessary for muscle contraction and relaxation. So, the consumption of potassium through diet from grains, soybeans, potatoes, nuts, corn, tomatoes, kiwi, bananas, melons, etc., should be limited. During the chronic kidney injury, like potassium, excretion of phosphorus is also decreased, contributing to elevated levels of phosphorus in the blood. As phosphate balances with the calcium levels in the skeletal muscle, an inequality contributes to substantial calcium deficiency and bone diseases. In brief, improper intake of carbohydrates and proteins is handled with an energy goal of 1,600 kcal per day i.e., $60 \%$ of which emanates from carbohydrates and $40 \%$ from proteins.

A recent study reports that following the strict diet control regimen in stage 4 CKD accomplished a remarkable regulation of blood lipid and glucose levels (Kim, 2014). Nevertheless, patient compliance with the prescribed food intake appears to be gender-based, e.g., the measured level of compliance to a specific diet in a Finnish cohort DN analysis stated that the patients were female, aged, and had a longer period of diabetes (Ahola et al., 2018). Therefore, patient education awareness for strict adherence may also be a key factor of DN's regulation by diet.

\section{NOVEL DRUGS FOR NEPHROPATHY}

Some agents for DN are discussed in brief, and the treatment strategies comprise stringent blood glucose level control and blood pressure. Novel therapeutics is continuously being studied such as novel molecules that could interfere with the pathogenic molecular and cellular targets within the kidney, like podocytes (Dande et al., 2017).

\section{SODIUM-GLUCOSE COTRANSPORTER 2 INHIBITORS}

SGLT2 in the proximal tubule of S1 portion is one of the key factors of hyperglycemia and glomerular hyperfiltration and may lead to DN progression. A novel class of oral hypoglycemic agents, SGLT2 inhibitors is especially promising at the starting phases of DN and is capable of suppressing the diabetic hyperfiltration independently of their effects on glucose levels, while reducing glucose reabsorption and increased glycosuria (Azizi et al., 2007; Gonzalez et al., 2020).

\section{ENDOTHELIN RECEPTOR ANTAGONISTS}

Endothelin-1 (ET-1), an effective vasoconstrictor, was studied extensively in laboratory and clinical trials to test the efficacy as a RAAS-blocking agent for ET-1 inhibitors. In tubules, glomerular hyperfiltration prompts protein overload which stimulates overexpression of ET-1, cell proliferation, and interstitial inflammation, eventually leading to progressive damage to the kidney (Dande et al., 2017). Furthermore, protein overload tends to induce ET-1 expression, which can modify glomerular perm selectivity by increased levels of $\beta$-arrestin- 1 . ET-1 can be antagonized by decreasing its development by inhibiting the ET-1 converting enzyme that produces the biologically active ET-1 from its large ET-1 precursor or by mixed or selective inhibition of the $E T_{A} R$ and $E T_{B} R$ receptors (Gentile et al., 2014).

\section{NF-kB INHIBITORS}

NF-kB is a transcription factor which regulates cytokine encoding genes expressions, cell adhesion molecules, growth factors, and certain proteins in the acute phase. NF-kB can be triggered by many agents, such as cytokines, ROS, inhaled particles, ultraviolet irradiation, and germs, via classical or alternate signaling pathways (Liu et al., 2017). Inflammation induces inappropriate activation of NF-kB, whereas complete, continuous inhibition of NF-kB could lead to apoptosis, change in development of immune cell, and deferred cell growth (Mussbacher et al., 2019). Therefore, NF-kB modulator strategies eventually have the advantage of treating multiple diseases, such as DN.

\section{GENE THERAPY}

Many upregulating genes have been recently identified for diabetic nephropathy. An aldo-keto-reductase family of renalspecific reductase has just been identified in a diabetic mouse. This can be used as an effective goal for gene treatment in the case of renal diabetes complications. The mitochondrial genes defined in nephropathic rats are cytochrome Oxidase I, III, and NADH dehydrogenase IV (Wada et al., 2002; Oates, 2010).

Translocase inner mitochondrial membrane-44 (Tim44), a nuclear-encoded mitochondrial gene, is up-regulated in the diabetic kidneys, and also acts as a molecular therapy strategic target in mitochondria. Tim44 enables the import of proteins from cytosol into mitochondria and may engage in earlier pathobiological actions in DN (i.e., oxidative phosphorylation is triggered as glucose reaches the cell) (Wallner et al., 2002; Bonora et al., 2006). During the preprotein import motor's reaction cycle, the key feature of Tim44 is complex conformation with $\mathrm{mtHsp} 70$. Apart from the mitochondrial length of DNA and point-mutations described in diabetes-related genetic diseases, it is possible that hyperglycemia can lead to apoptosis using disrupting oxidative phosphorylation and thus intruding with the mitochondrial import mechanism (Taylor and Turnbull, 2005). Evidence shows that in hyperglycemic conditions, Tim44 is triggered and complexes with $\mathrm{mtHsp} 70$. This indicates that in DN, Tim44 could be engaged in apoptosis of various types of cell. 


\section{STEM CELL THERAPY}

Stem cell therapy is considered a promising method for therapeutics in clinical use. It opens new ways to the advancement of renal function and structural reconstruction of kidneys, with the ability for self-renewal and a high capacity for proliferation and differentiation. It unlocks new doors for treating nearly all human disorders with the focus on limitless amplification, plasticity, and genetic modification. The use of stem cell therapy has been extensively studied for treating several diseases such as cardiac, immunological, renal, and neurological diseases (Petrie Aronin and Tuan, 2010; Liu et al., 2020). The use of stem cells for kidney disorders is also a potential therapeutic approach. Increasing findings obtained in acute kidney injury models and CKD shows that stem cells possess a therapeutic capacity for renal injury reconstruction, maintaining kidney function, structure, and extending animal life. Initially, the results were due to stem cells that implant damaged tissue, distinguish, and substitute damaged cells (Rota et al., 2019). Potential stem cells can differentiate into specific cell types under suitable conditions according to their differentiation potential and could be classified into four groups, viz., unipotent, multipotent, pluripotent, and totipotent cells. Stem cells differentiate into kidney lineages and develop organoids. These lineage cells and organoids are for disease modeling and development and useful for organ transplantation (Zakrzewski et al., 2019).

\section{TRANSPLANTATION}

Pancreas and kidney transplantation are one of the effective therapeutic measures for ESRD in T1DM patients, with the majority maintaining insulin independence and avoiding DN recurrence (Bohman et al., 1985; Lerner, 2008). A series of biopsies of CKD patients who had pancreas transplantation showed a decline in albuminuria and reversal of DN lesions (Fioretto et al., 1998). Some of these advantages are compensated by arteriolar hyalinosis and interstitial fibrosis caused by inhibitors of calcineurin such as cyclosporine. The deposition interstitial collagen reported at five years was enhanced by tubule interstitial remodeling, and vascular modifications were not affected (Fioretto et al., 2006).

\section{CONCLUSION}

Our review suggests the early diagnosis of microalbuminuria will help to identify patients with DN at the earliest. Poor blood sugar level control, longer duration of the DM, uncontrolled blood pressure, smoking, and physical inactivity are some of the risk factors for DN mentioned in the literature. Controlled diet, improved glycemic control, protein restriction coupled with sodium and potassium could help to manage the condition. Transplantation, stem cells, novel molecules for therapeutic, and treatments are warranted for DN control and treatments.

\section{REFERENCES}

Ahmad, T., Ulhaq, I., Mawani, M. and Islam, N. (2017) Microalbumin- uria in type-2 diabetes mellitus; the tip of iceberg of diabetic complications. Pak. J. Med. Sci. 33, 519-523.

Ahola, K. A. J., Forsblom, C. and Groop, P. H. (2018) Adherence to special diets and its association with meeting the nutrient recommendations in individuals with type 1 diabetes. Acta Diabetol. 55, 843-851.

Amalan, V. and Vijayakumar, N. (2015) Antihyperglycemic effect of p-coumaric acid on streptozotocin induced diabetic rats. Indian J. Appl. Res. 5, 2249-2255.

Amalan, V., Vijayakumar, N. and Ramakrishnan, A. (2015) p-Coumaric acid regulates blood glucose and antioxidant levels in streptozotocin induced diabetic rats. J. Chem. Pharm. Res. 7, 831-839.

Anders, H. J., Davis, J. M. and Thurau, K. (2016) Nephron protection in diabetic kidney disease. N. Engl. J. Med. 375, 2096-2098.

Azizi, M., Ménard, J., Bissery, A., Guyene, T. T. and Bura-Rivière, A. (2007) Hormonal and hemodynamic effects of aliskiren and valsartan and their combination in sodium-replete normotensive individuals. Clin. J. Am. Soc. 2, 947-955.

Berhane, A. M., Weil, E. J., Knowler, W. C., Nelson, R. G. and Hanson, R. L. (2011) Albuminuria and estimated glomerular filtration rate as predictors of diabetic end-stage renal disease and death. Clin. J. Am. Soc. Nephrol. 6, 2444-2451.

Bohman, S. O., Tydén, G., Wilczek, H., Lundgren, G., Jaremko, G., Gunnarsson, R., Ostman, J. and Groth, C. G. (1985) Prevention of kidney graft diabetic nephropathy by pancreas transplantation in man. Diabetes 34, 306-308.

Bonora, E., Evangelisti, C., Bonichon, F., Tallini, G. and Romeo, G. (2006) Novel germline variants identified in the inner mitochondrial membrane transporter TIMM44 and their role in predisposition to oncocytic thyroid carcinomas. Br. J. Cancer 95, 1529-1536.

Börnhorst, C., Russo, P., Veidebaum, T., Tornaritis, M., Molnár, D., Lissner, L., Mårild, S., De Henauw, S., Moreno, L. A., Floegel, A., Ahrens, W. and Wolters, M. (2020) The role of lifestyle and nonmodifiable risk factors in the development of metabolic disturbances from childhood to adolescence. Int. J. Obes. (Lond.) 44, 2236-2245.

Caramori, M. L., Fioretto, P. and Mauer, M. (2000) The need for early predictors of diabetic nephropathy risk: is albumin excretion rate sufficient? Diabetes 49, 1399-1408.

Chatzikyrkou, C., Menne, J., Izzo, J., Viberti, G., Rabelink, T., Ruilope, L. M., Rump, C., Mertens, P. R. and Haller, H. (2017) Predictors for the development of microalbuminuria and interaction with renal function. J. Hypertens 35, 2501-2509.

Chou, K. M., Lee, C. C., Chen, C. H. and Sun, C. Y. (2013) Clinical value of NGAL, L-FABP and albuminuria in predicting GFR decline in type 2 diabetes mellitus patients. PLOS ONE 8, e54863.

Conway, B. R., Manoharan, D., Manoharan, D, Jenks, S., Dear, J. W., McLachlan, S., Strachan, M. W. and Price, J. F. (2012) Measuring urinary tubular biomarkers in type 2 diabetes does not add prognostic value beyond established risk factors. Kidney Int. 82, 812818.

Dande, R. R., Peev, V., Altintas, M. M. and Reiser, J. (2017) Soluble urokinase receptor and the kidney response in diabetes mellitus. J. Diabetes Res. 2017, 3232848.

De Sanctis, V., Incorvaia, C., Soliman, A. T., Candini, G., Pepe, A., Kattamis, C., Soliman, N. A., Elsedfy, H. and Kholy, M. E. (2015) Does insulin like growth factor-1 (IGF-1) deficiency have a "protective" role in the development of diabetic retinopathy in thalassamia major patients? Mediterr. J. Hematol. Infect. Dis. 7, e2015038.

Dellamea, B. S., Pinto, L. C., Leitao, C. B., Santos, K. G. and Canani, L. H. (2014) Endothelial nitric oxide synthase gene polymorphisms and risk of diabetic nephropathy: a systematic review and metaanalysis. BMC Med. Genet. 15, 9.

Eberhard, J., Drosos, Z., Tiemann, M., Jepsen, S. and Schröder, J. M. (2006) Immunolocalization of lactoferrin in healthy and inflamed gingival tissues. J. Periodontol. 77, 472-478.

Fioretto, P., Steffes, M. W., Sutherland, D. E., Goetz, F. C. and Mauer, M. (1998) Reversal of lesions of diabetic nephropathy after pancreas transplantation. N. Engl. J. Med. 339, 69-75.

Fioretto, P., Sutherland, D. E., Najafian, B. and Mauer, M. (2006) Remodeling of renal interstitial and tubular lesions in pancreas transplant recipients. Kidney Int. 69, 907-912. 
Fu, H., Liu, S., Bastacky, S. I., Wang, X., Tian, X. J. and Zhou, D. (2019) Diabetic kidney diseases revisited: a new perspective for a new era. Mol. Metab. 30, 250-263.

Gall, M. A., Hougaard, P., Borch-Johnsen, K. and Parving, H. H. (1997) Risk factors for development of incipient and overt diabetic nephropathy in patients with non-insulin dependent diabetes mellitus: prospective, observational study. BMJ 314, 783-788.

Gentile, G., Mastroluca, D., Ruggenenti, P. and Remuzzi, G. (2014) Novel effective drugs for diabetic kidney disease? or not? Expert Opin. Emerg. Drugs 19, 571-601.

Gheith, O., Farouk, N., Nampoory, N., Halim, M. A. and Al-Otaibi, T. (2016) Diabetic kidney disease: world wide difference of prevalence and risk factors. J. Nephropharmacol. 5, 49-56.

Gonzalez, D. E., Foresto, R. D. and Ribeiro, A. B. (2020) SGLT-2 inhibitors in diabetes: a focus on renoprotection. Rev. Assoc. Med. Bras. 66, s17-s24.

Hill, N. R., Fatoba, S. T., Oke, J. L., Hirst, J. A., O'Callaghan, C. A., Lasserson, D. S. and Hobbs, F. D. R. (2016) Global prevalence of chronic kidney disease - a systematic review and meta-analysis. PLOS ONE 11, e0158765.

Kanauchi, N., Ookawara, S., Ito, K., Mogi, S., Yoshida, I., Kakei, M., Ishikawa, S. E., Morishita, Y. and Tabei, K. (2015) Factors affecting the progression of renal dysfunction and the importance of salt restriction in patients with type 2 diabetic kidney disease. Clin. Exp. Nephrol. 19, 1120-1126.

Kim, H. Y. (2014) Nutritional intervention for a patient with diabetic nephropathy. Clin. Nutr. Res. 3, 64-68.

Kim, S. S., Song, S. H., Kim, I. J., Jeon, Y. K., Kim, B. H., Kwak, I. S. Lee, E. K. and Kim, Y. K. (2013) Urinary cystatin C and tubular proteinuria predict progression of diabetic nephropathy. Diabetes Care 36, 656-661.

Kitada, M., Ogura, Y., Monno, I. and Koya, D. (2018) A low-protein diet for diabetic kidney disease: its effect and molecular mechanism, an approach from animal studies. Nutrients 10, 544 .

Kopel, J., Pena-Hernandez, C. and Nugent, K. (2019) Evolving spectrum of diabetic nephropathy. World J. Diabetes 10, 269-279.

Krock, B. L., Skuli, N. and Simon, M. C. (2011) Hypoxia-induced angiogenesis: good and evil. Genes Cancer 2, 1117-1133.

Lacquaniti, A., Donato, V., Pintaudi, B., Di Vieste, G., Chirico, V., Buemi, A., Di Benedetto, A., Arena, A. and Buemi, M. (2013) "Normoalbuminuric" diabetic nephropathy: tubular damage and NGAL. Acta Diabetol. 50, 935-942.

Lerner, S. M. (2008) Kidney and pancreas transplantation in type 1 diabetes mellitus. Mt. Sinai J. Med. 75, 372-384.

Li, J. Y., Chen, X. X., Lu, X. H., Zhang, C. B., Shi, Q. P. and Feng, L. (2018) Elevated RBP4 plasma levels were associated with diabetic retinopathy in type 2 diabetes. Biosci. Rep. 38, BSR20181100.

Liu, A. G., Ford, N. A., Hu, F. B., Zelman, K. M., Mozaffarian, D. and Kris-Etherton, P. M. (2017) A healthy approach to dietary fats: understanding the science and taking action to reduce consumer confusion. Nutr. J. 16, 53.

Liu, D., Cheng, F., Pan, S. and Liu, Z. (2020) Stem cells: a potential treatment option for kidney diseases. Stem Cell Res. Ther. 11, 249.

Lu, B., Wen, J., Song, X. Y., Dong, X. H., Yang, Y. H., Zhang, Z. Y., Zhao, N. Q., Ye, H. Y., Mou, B., Chen, F. L., Liu, Y., Shen, Y., Wang, X. C., Zhou, L. N., Li, Y. M., Zhu, X. X. and Hu, R. M. (2017) High prevalence of albuminuria in population-based patients diagnosed with type 2 diabetes in the Shanghai downtown. Diabetes Res. Clin. Pract. 75, 184-192.

Mohammad, G. and Siddiquei, M. M. (2012) Role of matrix metalloproteinase-2 and -9 in the development of diabetic retinopathy. $J$. Ocul. Biol. Dis. Infor. 5, 1-8.

Motawi, T. K., Shehata, N. I., EINokeety, M. M. and El-Emady, Y. F. (2018) Potential serum biomarkers for early detection of diabetic nephropathy. Diabetes Res. Clin. Pract. 136, 150-158.

Mussbacher, M., Salzmann, M., Brostjan, C., Hoesel, B., Schoergenhofer, C., Datler, H., Hohensinner, P., Basílio, J., Petzelbauer, P., Assinger, A. and Schmid, J. A. (2019) Cell type-specific roles of NF$\kappa \mathrm{B}$ linking inflammation and thrombosis. Front. Immunol. 10, 85.

Narres, M., Claessen, H., Droste, S., Kvitkina, T., Koch, M., Kuss, O. and Icks, A. (2016) The incidence of end-stage renal disease in the diabetic (compared to the non-diabetic) population: a systematic review. PLoS ONE 11, e0147329.

Navarro, J. F., Milena, F. J., Mora, C., Leon, C., Claverie, F., Flores, C. and Garcia, J. (2005) Tumor necrosis factor-alpha gene expression in diabetic nephropathy: relationship with urinary albumin excretion and effect of angiotensin-converting enzyme inhibition. Kidney Int. Suppl. (99), S98-S102.

Neal, B., Perkovic, V., Mahaffey, K. W., de Zeeuw, D., Fulcher, G., Erondu, N., Shaw, W., Law, G., Desai, M. and Matthews, D. R.; CANVAS Program Collaborative Group (2017) Canagliflozin and cardiovascular and renal events in type 2 diabetes. N. Engl. J. Med. 377, 644-657.

Nielsen, H. B., Almeida, M., Juncker, A. S., Rasmussen, S., Li, J., Sunagawa, S., Plichta, D. R., Gautier, L., Pedersen, A. G., Le Chatelier, E., Pelletier, E., Bonde, I., Nielsen, T., Manichanh, C., Arumugam, M., Batto, J. M., Quintanilha Dos Santos, M. B., Blom, N., Borruel, N., Burgdorf, K. S., Boumezbeur, F., Casellas, F., Doré, J., Dworzynski, P., Guarner, F., Hansen, T., Hildebrand, F., Kaas, R. S., Kennedy, S., Kristiansen, K., Kultima, J. R., Léonard, P., Levenez, F., Lund, O., Moumen, B., Le Paslier, D., Pons, N., Pedersen, O., Prifti, E., Qin, J., Raes, J., Sørensen, S., Tap, J., Tims, S., Ussery, D. W., Yamada, T.; MetaHIT Consortium, Renault, P., Sicheritz-Ponten, T., Bork, P., Wang, J., Brunak, S., Ehrlich, S. D. (2014) Identification and assembly of genomes and genetic elements in complex metagenomic samples without using reference genomes. Nat. Biotechnol. 32, 822-828.

Nielsen, S. E., Andersen, S., Zdunek, D., Hess, G., Parving, H. H. and Rossing, P. (2011) Tubular markers do not predict the decline in glomerular filtration rate in type 1 diabetic patients with overt nephropathy. Kidney Int. 79, 1113-1118.

Niewczas, M. A., Gohda, T., Skupien, J., Smiles, A. M., Walker, W. H., Rosetti, F., Cullere, X., Eckfeldt, J. H., Doria, A., Mayadas, T. N., Warram, J. H. and Krolewski, A. S. (2012) Circulating TNF receptors 1 and 2 predict ESRD in type 2 diabetes. J. Am. Soc. Nephrol. 23, $507-515$

Oates, P. J. (2010) Aldose reductase inhibitors and diabetic kidney disease. Curr. Opin. Investig. Drugs 11, 402-417.

Oh, S. W., Kim, S., Na, K. Y., Chae, D. W., Kim, S., Jin, D. C. and Chin, H. J. (2012) Clinical implications of pathologic diagnosis and classification for diabetic nephropathy. Diabetes Res. Clin. Pract. 97, 418-424.

Oltean, S., Coward, R., Collino, M. and Baelde, H. (2017) Diabetic nephropathy: novel molecular mechanisms and therapeutic avenues. Biomed. Res. Int. 2017, 3146524.

Otoda, T., Kanasaki, K. and Koya, D. (2014) Low-protein diet for diabetic nephropathy. Curr. Diab. Rep. 14, 523.

Panduru, N. M., Forsblom, C., Saraheimo, M., Thorn, L., Bierhaus, A., Humpert, P. M. and Groop, P. H.; FinnDiane Study Group (2013) Urinary liver-type fatty acid-binding protein and progression of diabetic nephropathy in type 1 diabetes. Diabetes Care 36, 2077 2083.

Papadopoulou-Marketou, N., Kanaka-Gantenbein, C., Marketos, N., Chrousos, G. P. and Papassotiriou, I. (2017) Biomarkers of diabetic nephropathy: a 2017 update. Crit. Rev. Clin. Lab. Sci. 54, 326-342.

Perry, R. J. and Shulman, G. I. (2020) Sodium-glucose cotransporter-2 inhibitors: understanding the mechanisms for therapeutic promise and persisting risks. J. Biol. Chem. 295, 14379-14390.

Petrie Aronin, C. E. and Tuan, R. S. (2010) Therapeutic potential of the immunomodulatory activities of adult mesenchymal stem cells. Birth Defects Res. C Embryo Today 90, 67-74

Pettitt, D. J., Saad, M. F., Bennett, P. H., Nelson, R. G. and Knowler, W. C. (1990) Familial predisposition to renal disease in two generations of Pima Indians with type 2 (non-insulin-dependent) diabetes mellitus. Diabetologia 33, 438-443.

Pugliese, G., Penno, G., Natali, A., Barutta, F., Di Paolo, S., Reboldi, G., Gesualdo, L. and De Nicola, L.; Italian Diabetes Society and the Italian Society of Nephrology (2020) Diabetic kidney disease: new clinical and therapeutic issues. Joint position statement of the Italian Diabetes Society and the Italian Society of Nephrology on "The natural history of diabetic kidney disease and treatment of hyperglycemia in patients with type 2 diabetes and impaired renal function". J. Nephrol. 33, 9-35.

Kowluru, R. A. (2010) Role of Matrix metalloproteinase-9 in the devel- 
opment of diabetic retinopathy and its regulation by $\mathrm{H}$-ras. Invest. Ophthalmol. Vis. Sci. 51, 4320-4326.

Retnakaran, R., Cull, C. A., Thorne, K. I., Adler, A. I. and Holman, R. R.; UKPDS Study Group (2006) Risk factors for renal dysfunction in type 2 diabetes: U.K. prospective diabetes study 74. Diabetes 55, $1832-1839$.

Rojas, M. A., Zhang, W., Xu, Z., Nguyen, D. T., Caldwell, R. W. and Caldwell, R. B. (2011) Interleukin 6 has a critical role in diabetesinduced retinal vascular inflammation and permeability. Invest Ophthalmol. Vis. Sci. 52, 1003.

Rota, C., Morigi, M. and Imberti, B. (2019) Stem cell therapies in kidney diseases: progress and challenges. Int. J. Mol. Sci. 20, 2790.

Sabbisetti, V. S., Waikar, S. S., Antoine, D. J., Smiles, A., Wang, C., Ravisankar, A., Ito, K., Sharma, S., Ramadesikan, S., Lee, M., Briskin, R., De Jager, P. L., Ngo, T. T., Radlinski, M., Dear, J. W. Park, K. B., Betensky, R., Krolewski, A. S. and Bonventre, J. V. (2014) Blood kidney injury molecule-1 is a biomarker of acute and chronic kidney injury and predicts progression to ESRD in type diabetes. J. Am. Soc. Nephrol. 25, 2177-2186.

Saran, R., Robinson, B., Abbott, K. C., Agodoa, L. Y., Albertus, P., Ayanian, J., Balkrishnan, R., Bragg-Gresham, J., Cao, J., Chen, J. L., Cope, E., Dharmarajan, S., Dietrich, X., Eckard, A., Eggers, P. W. Gaber, C., Gillen, D., Gipson, D., Gu, H., Hailpern, S. M., Hall, Y. N., Han, Y., He, K., Hebert, H., Helmuth, M., Herman, W., Heung, M., Hutton, D., Jacobsen, S. J., Ji, N., Jin, Y., Kalantar-Zadeh, K., Kapke, A., Katz, R., Kovesdy, C. P., Kurtz, V., Lavalee, D., Li, Y., Lu, Y., McCullough, K., Molnar, M. Z., Montez-Rath, M., Morgenstern, H., Mu, Q., Mukhopadhyay, P., Nallamothu, B., Nguyen, D. V., Norris, K. C., O'Hare, A. M., Obi, Y., Pearson, J., Pisoni, R., Plattner, B., Port, F. K., Potukuchi, P., Rao, P., Ratkowiak, K., Ravel, V., Ray, D., Rhee, C. M., Schaubel, D. E., Selewski, D. T., Shaw, S., Shi, J., Shieu, M., Sim, J. J., Song, P., Soohoo, M., Steffick, D., Streja, E., Tamura, M. K., Tentori, F., Tilea, A., Tong, L., Turf, M., Wang, D., Wang, M., Woodside, K., Wyncott, A., Xin, X., Zang, W., Zepel, L., Zhang, S., Zho, H., Hirth, R. A. and Shahinian, V. (2017) US Renal Data System 2016 Annual Data Report: epidemiology of kidney disease in the United States. Am. J. Kidney Dis. 69, A7-A8.

Satko, S. G., Langefeld, C. D., Daeihagh, P., Bowden, D. W., Rich, S. S. and Freedman, B. I. (2002) Nephropathy in siblings of African Americans with overt type 2 diabetic nephropathy. Am. J. Kidney Dis. 40, 489-494.

Schrijvers, B. F., De Vriese, A. S. and Flyvbjerg, A. (2004) From hyperglycemia to diabetic kidney disease: the role of metabolic, hemodynamic, intracellular factors and growth factors/cytokines. Endocr. Rev. 25, 971-1010.

Scott, L. J., Warram, J. H., Hanna, L. S., Laffel, L. M., Ryan, L. and Krolewski, A. S. (2001) A nonlinear effect of hyperglycemia and current cigarette smoking are major determinants of the onset of microalbuminuria in type 1 diabetes. Diabetes 50, 2842-2849.

Shahbazian, H. and Rezaii, I. (2013) Diabetic kidney disease; review of the current knowledge. J. Renal Inj. Prev. 2, 73-80.

Skupien, J., Warram, J. H., Smiles, A., Galecki, A., Stanton, R. C. and Krolewski, A. S. (2014) Improved glycemic control and risk of ESRD in patients with type 1 diabetes and proteinuria. J. Am. Soc. Nephrol. 25, 2916-2925.

Smith, A. and Harris, C. (2018) Type 1 diabetes: management strategies. Am. Fam. Physician 98, 154-162.

Sulaiman, M. K. (2019) Diabetic nephropathy: recent advances in pathophysiology and challenges in dietary management. Diabetol. Metab. Syndr. 11, 7.

Taylor, R. W. and Turnbull, D. M. (2005) Mitochondrial DNA mutations in human disease. Nat. Rev. Genet. 6, 389-402.

Tervaert, T. W., Mooyaart, A. L., Amann, K., Cohen, A. H., Cook, H. T., Drachenberg, C. B., Ferrario, F., Fogo, A. B., Haas, M., de Heer, E., Joh, K., Noël, L. H., Radhakrishnan, J., Seshan, S. V., Bajema, I. M. and Bruijn, J. A.; Renal Pathology Society (2010) Pathologic classification of diabetic nephropathy. J. Am. Soc. Nephrol. 21, 556-563.

Tonneijck, L., Muskiet, M. H. A., Smits, M. M., van Bommel, E. J., Heerspink, H. J. L., van Raalte, D. H. and Joles, J. A. (2017) Glomerular hyperfiltration in diabetes: mechanisms, clinical significance, and treatment. J. Am. Soc. Nephrol. 28, 1023-1039.

Trimeche, A., Selmi, Y., Ben Slama. F., Ben Amara, H., Hazar, I., Ben Mami, F. and Achour, A. (2013) Effect of protein restriction on renal function and nutritional status of type 1 diabetes at the stage of renal impairment. Tunis. Med. 91, 117-122.

Vallon, V. (2015) The mechanisms and therapeutic potential of SGLT2 inhibitors in diabetes mellitus. Annu. Rev. Med. 66, 255-270.

Wada, J., Makino, H. and Kanwar, Y. S. (2002) Gene expression and identification of gene therapy targets in diabetic nephropathy. Kidney Int. 61, S73-S78.

Wallner, E. I., Wada, J., Lin, S., Pan, X., Reddy, J. K., Chugh, S. S. and Kanwar, Y. S. (2002) Renal gene expression in embryonic and newborn diabetic mice. Exp. Nephrol. 10, 130-138.

Wanner, C., Inzucchi, S. E., Lachin, J. M., Fitchett, D., von Eynatten, M., Mattheus, M., Johansen, O. E., Woerle, H. J., Broedl, U. C. and Zinman, B.; EMPA-REG OUTCOME Investigators (2016) Empagliflozin and progression of kidney disease in type 2 diabetes. $N$. Engl. J. Med. 375, 323-334.

Werner, N., Nickenig, G. and Sinning, J. M. (2018) Complex PCl procedures: challenges for the interventional cardiologist. Clin. Res. Cardiol. 107, 64-73.

Young, B. A., Maynard, C. and Boyko, E. J. (2003) Racial differences in diabetic nephropathy, cardiovascular disease, and mortality in a national population of veterans. Diabetes Care 26, 2392-2399.

Zakrzewski, W., Dobrzyński, M., Szymonowicz, M. and Rybak, Z. (2019) Stem cells: past, present, and future. Stem Cell Res. Ther. 10,68 .

Zeni, L., Norden, A. G. W., Cancarini, G. and Unwin, R. J. (2017) A more tubulocentric view of diabetic kidney disease. J. Nephrol. 30, 701-717.

Zha, Y. and Qian, Q. (2017) Protein nutrition and malnutrition in CKD and ESRD. Nutrients 9, 208. 